\title{
A Review of Boundary Objects in Classification Research
}

\author{
Eva Hourihan Jansen \\ University of Toronto \\ 140 St. George St. \\ eva.jansen@utoronto.ca
}

\begin{abstract}
The goal of this paper is to explore the empirical aptness of a conceptual framework for the study of an international standard classification system by considering epistemological assumptions underlying its use in classification research to date. I survey reviews and empirical inquiry in LIS that feature the concept boundary object, (Star \& Griesemer, 1989) and discuss some implications for classification research. I discuss the problems posed when predominant discourses concerning classification research inhibit our understanding of classification practices as socially, historically and culturally constructed. I conclude with proposing inquiry into international standard occupational classification as a way of exploring the limits of the boundary object concept within the context of globalized standards and local practices.
\end{abstract}

\section{INTRODUCTION}

Knowledge organization and classification in international information retrieval is a topic of concern in classification research. Mai (2003), considering the context of bibliographic classification, has argued for the use of general classifications to provide access to collections nationally and internationally. Campbell (2003), comparing bibliographic and statistical classification schemes, observed that the abstraction required for harmonized data diminished the context that contributed to meaning of the data used to construct the scheme. The proposal of general or standard classifications and the importance of context are not new concepts in information science. However, we know little about the role of standard classifications as they are enacted among different contexts and across expanding levels of scale.

This is the space reserved for copyright notices.

Advances in Classification Research, 2012, October 26, 2012, Baltimore, MD, USA.

Copyright notice continues right here.
The concept of boundary object has been a helpful construct for researchers discussing the design and use of classification systems in institutional settings. While a number of empirical studies have employed the concept to discuss the consequences of classification systems, none have offered a detailed discussion of the empirical aptness of the concept for the study of standard international classification systems.

\section{APPROACH}

I describe the origin of the concept boundary object (Star \& Greisemer, 1989) and consider contributions made broadly in LIS and related disciplines through review literature. Then I consider its enactment in two examples of LIS research concerning bibliographic classification more particularly. I assess these studies in relation to Hjorland's (2005) concern with characterizing the influence of empiricist, rationalist and positivist epistemologies and Day's (2011) call for conceptual critique of theoretical models that extends to practice, method and the notion of theory and disciplinary foundation. I conclude with a discussion of the empirical aptness of the boundary object concept for approaching the study of a standard international classification system.

\section{CONCLUSIONS}

The findings of this analysis suggest that despite the adaptation of a social constructivist theoretical framework in classification research, its use continues to demonstrate a tendency toward a positivist epistemological paradigm. Letting go of such assumptions is essential for moving towards critical inquiry of the political and ethical dimensions of classification practices; studying standard international classification and contributing to theories of classification.

\section{CONTRIBUTION TO CLASSIFICATION RESEARCH}

This research offers a conceptual analysis and discussion of the empirical aptness of a popular constructivist approach to understanding classification practices with a view to informing future directions in methodology for classification research that is concerned with standard classification systems in global and local contexts.

\section{Keywords}

classification research, boundary object, epistemology. 